\title{
Prostate Acinar Adenocarcinoma, Microcystic Variant
}

National Cancer Institute

\section{Source}

National Cancer Institute. Prostate Acinar Adenocarcinoma, Microcystic Variant. NCI

Thesaurus. Code C160817.

A variant of acinar prostate adenocarcinoma characterized by the presence of microcystic foci in radical prostatectomy specimens. 